\title{
Effect of wall construction materials over indoor air quality in humid and hot climate
}

\author{
Modeste Kameni Nematchoua ${ }^{\mathrm{a}, *}$, René Tchinda ${ }^{\mathrm{b}}$, José A. Orosa ${ }^{\mathrm{c}, *}$, \\ Wagner Augusto Andreasi ${ }^{\mathrm{d}}$ \\ a Environmental Energy Technologies Laboratory, University of Yaoundé I, Cameroon \\ ${ }^{\mathrm{b}}$ LISIE, University Institute of Technology Fotso Victor, University of Dschang, Cameroon \\ ${ }^{\mathrm{c}}$ Department of Energy and M.P. Escuela Técnica Superior de N. y M, University of Coruña, Paseo de Ronda 51, 15011 A Coruña, Spain \\ ${ }^{\mathrm{d}}$ Laboratory of Analysis and Development of Buildings, Federal University of Mato Grosso do Sul, Brazil
}

\section{A R T I C L E I N F O}

\section{Article history:}

Received 30 November 2014

Received in revised form

8 May 2015

Accepted 11 May 2015

Available online 9 June 2015

\section{Keywords:}

Materials

Indoor ambience

Humid

Hot ambiences

Hourly

\begin{abstract}
A B S T R A C T
In the present research work, a mix of 15 modern and old office buildings were sampled and classified in accordance with their building construction materials, along with the indoor ambience conditions. From this hourly study, it was found that the season was not the more important parameter, despite there being a tendency towards a similar kind of ambience during the rainy season. On the other hand, it showed a clear difference between modern and old buildings with plaster coating, during the period of occupation. Specifically, a better indoor ambience prevailed in the old buildings. At the same time, when marble and plaster coatings were analysed in the old buildings, a clear difference in indoor ambience was felt at the time of opening the office. This shows that a better indoor ambience prevailed during the dry period in the old buildings when marble coatings were used. Finally, the same effect, but not as pronounced, seen in the indoor ambience during the opening of the office, was obtained in new buildings that had marble coating.

Finally, the procedure obtained could be the much sought-after solution to the problem stated by researchers in the past and future research works relating to this new methodology could help us define the optimal improvement in real buildings to reduce energy consumption, and its related carbon dioxide emissions, at minimal economical cost.
\end{abstract}

(c) 2015 Elsevier Ltd. All rights reserved.

\section{Contents}

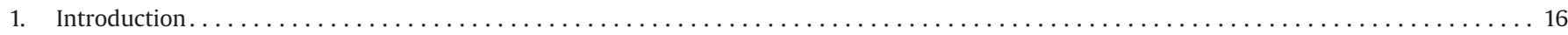

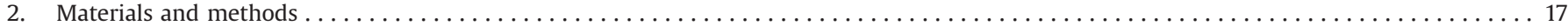

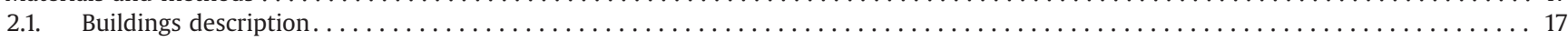

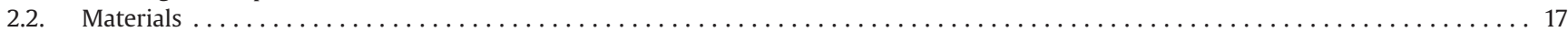

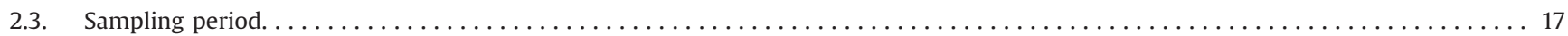

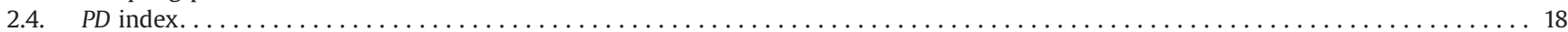

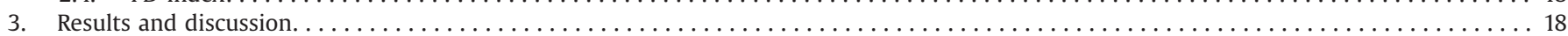

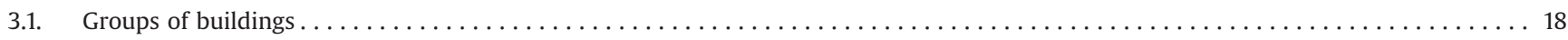

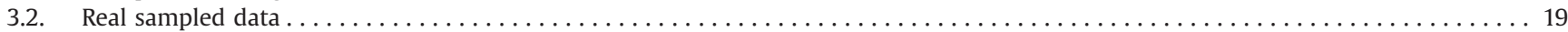

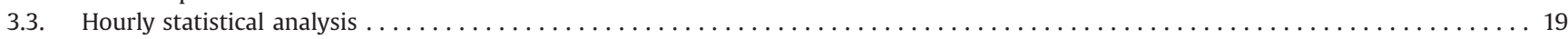

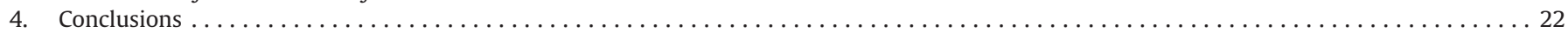

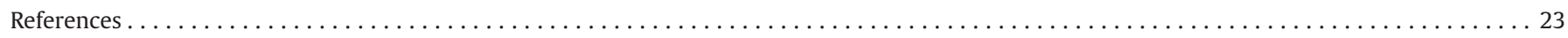

\footnotetext{
*Corresponding authors.
}

\section{Introduction}

Passive methods are an interesting design parameter that allows us to improve indoor ambiences by means of an adequate understanding of the processes and physics of building construction. Notable 
developments were achieved in the past few years to define building thermal processes, but its hygroscopic effects have not been clearly defined. Different international research projects of the International Energy Agency have tried to define these effects and to develop building design guides based on this concept.

Despite the fact that different research works have developed building simulation tools, employing actual sampled data to validate them is required. In previous research works [1], the effect of permeable covering in a humid region of Spain was shown based on real sampled data and statistical studies. The main results showed a clear improvement of indoor ambiences of buildings with permeable internal coverings, like wood and plaster, in contrast with the other ambiences under impermeable internal coverings, like paint and plastic [2,3]. This same effect could be related, at the same time, with an average and immediate improvement in local thermal comfort [4-9] and energy saving [10]. Results show how permeable coverings allow construction materials in building walls to absorb very high humidity in the indoor air and release it when the humidity is very low. This effect showed a clear working behaviour during the unoccupied hours of the office buildings. During this period, the number of air exchanges is reduced, and the infiltrations by doors and windows are nearly null. Consequently, indoor ambience during the first hour of occupation was modified towards favourable conditions, thus reducing peak energy consumption during that period.

In sub-Saharan Africa, very few studies have been conducted to analyse the influence that different types of buildings have on indoor air quality. In accordance with previous research works, the thermal and hygroscopic effects of local materials used in new and old buildings can be of interest for engineers. The types of bricks employed in wall construction will also be analysed. Two types of brick materials are employed in Cameroon: parpen and earthen bricks. Owing to the different levels of permeability, they are expected to have some different kinds of effects over the indoor ambience. Other parameters, like permeability level of the wall's external coating were also analysed. To achieve these objectives, 15 office buildings located in the humid and hot region of the capital city of Cameroon were studied during two seasons, in accordance with the procedure developed by Toftum et al. [11].

\section{Materials and methods}

\subsection{Buildings description}

In the present research work, 15 types of office buildings were sampled and classified in accordance with their building construction materials. It must be clarified here, that old buildings were considered as those that were more than 25 years old. In particular, these old buildings are named B2, B6, B9, B11, B12, and B14 in the tables and figures, since they were built with earthen bricks.

On the other hand, the new buildings are named B1, B3, B4, B5, B7, B8, B10, B13 and B15, since they used parpen bricks, as we can see in Table 1. Finally, for favourable comparison, all buildings present the same wall structures and orientation. Some, have an internal coating that mostly consists of marble, which is often dressed in fabric wool. The outer layer of the wall is made of mud bricks and plaster in old buildings. In new buildings, bricks of parpen, plaster and paint are employed. An example of a wall segment is given in Fig. 1. The structure and characteristics of the buildings studied are reported in previous table. In some buildings, large windows occupied more than half the wall areas, and are covered by curtains, thus preventing light rays from entering indoors and doors are mostly made of wood. In accordance with previous research works, selected offices were naturally ventilated, and the cooling and heating systems were interrupted during the experimental studies. In these offices, we could found some computers and sometime TV as electrical equipments. There were still less than 8 employees during study period in the office. These workers were estimated having a sedentary occupation, which corresponds with a metabolic rate around of 1 met, in accordance with thermal comfort standards.

\subsection{Materials}

In this study different indoor air variables were sampled. Between others, variables like indoor air speed, indoor relative humidity, $\mathrm{CO}_{2}$ concentration and indoor air temperature were measured using a thermo-anemometer (model C.A 1226) and a $\mathrm{CO}_{2}$ Monitor (model CO200).

On the other hand, outdoor weather variables were sampled to consider the effect of weather and indoor conditions. In this sense, data relating to outdoor temperature, wind speed and relative humidity were collected from the national weather stations. It must be explained that all these equipments were calibrated before use, to ensure reliability and accuracy during the sampling processes. Furthermore, the sampling accuracy of each device is shown in Table 2.

\subsection{Sampling period}

In the present research work, a sampling process with frequencies of $10-20$ min was carried out during the working hours from 08:00 to 17:00, and during the unoccupied period from 17:30

Table 1

Some characteristic of offices studied in the buildings.

\begin{tabular}{|c|c|c|c|c|c|c|c|c|c|c|}
\hline Buildings & Altitude (m) & $\begin{array}{l}\text { Floor area } \\
\left(\mathrm{m}^{2}\right)\end{array}$ & Volume $\left(\mathrm{m}^{3}\right)$ & Height (m) & $\begin{array}{l}\text { External } \\
\text { coating }\end{array}$ & $\begin{array}{l}\text { Type of } \\
\text { brick }\end{array}$ & $\begin{array}{l}\text { Type of } \\
\text { building }\end{array}$ & Age (years) & $\begin{array}{l}\text { Window area } \\
\left(\mathrm{m}^{2}\right)\end{array}$ & $\begin{array}{l}\text { Door area } \\
\left(\mathrm{m}^{2}\right)\end{array}$ \\
\hline $\mathrm{B}_{7}$ & $782 \pm 2$ & 71.5 & 299.1 & 4.2 & Plaster & Parpen & New building & 2 & 0.18 & 1.46 \\
\hline $\mathrm{B}_{15}$ & $730 \pm 7$ & 47.5 & 137.7 & 2.9 & Marble & Parpen & New building & 7 & 0.50 & 1.90 \\
\hline $\mathrm{B}_{10}$ & $731 \pm 7$ & 36.0 & 126.0 & 3.5 & Plaster & Parpen & New building & 15 & 0.35 & 2.26 \\
\hline $\mathrm{B}_{13}$ & $763 \pm 2$ & 55.2 & 209.8 & 3.8 & Paint & Parpen & New building & 5 & 0.40 & 1.95 \\
\hline $\mathrm{B}_{3}$ & $784 \pm 5$ & 59.5 & 220.1 & 3.7 & Plaster & Parpen & New building & 18 & 0.66 & 3.75 \\
\hline $\mathrm{B}_{4}$ & $763 \pm 4$ & 96.0 & 288.0 & 3.0 & Plaster & Parpen & New building & 11 & 0.36 & 1.80 \\
\hline $\mathrm{B}_{5}$ & $762 \pm 8$ & 49.0 & 186.2 & 3.8 & Plaster & Parpen & New building & 5 & 0.75 & 1.71 \\
\hline $\mathrm{B}_{8}$ & $748 \pm 7$ & 32.0 & 121.6 & 3.8 & Paint & Parpen & New building & 22 & 1.20 & 3.00 \\
\hline $\mathrm{B}_{1}$ & $750 \pm 8$ & 80.0 & 280.0 & 3.5 & Plaster & Parpen & New building & 16 & 0.42 & 1.90 \\
\hline $\mathrm{B}_{9}$ & $696 \pm 5$ & 66.0 & 270.6 & 4.1 & Paint & Earth & Old building & 45 & 0.58 & 1.62 \\
\hline $\mathrm{B}_{11}$ & $734 \pm 5$ & 45.0 & 180.0 & 4.0 & Marble & Earth & Old building & 39 & 0.84 & 2.10 \\
\hline $\mathrm{B}_{12}$ & $717 \pm 3$ & 76.5 & 306.0 & 4.0 & Paint & Earth & Old building & 28 & 1.02 & 1.93 \\
\hline $\mathrm{B}_{2}$ & $762 \pm 3$ & 84.0 & 336.0 & 4.0 & Plaster & Earth & Old building & 31 & 0.70 & 2.28 \\
\hline $\mathrm{B}_{14}$ & $747 \pm 4$ & 35.7 & 149.9 & 4.2 & Plaster & Earth & Old building & 51 & 1.45 & 1.35 \\
\hline $\mathrm{B}_{6}$ & $761 \pm 3$ & 54.0 & 210.6 & 3.9 & Plaster & Earth & Old building & 32 & 088 & 2.20 \\
\hline
\end{tabular}




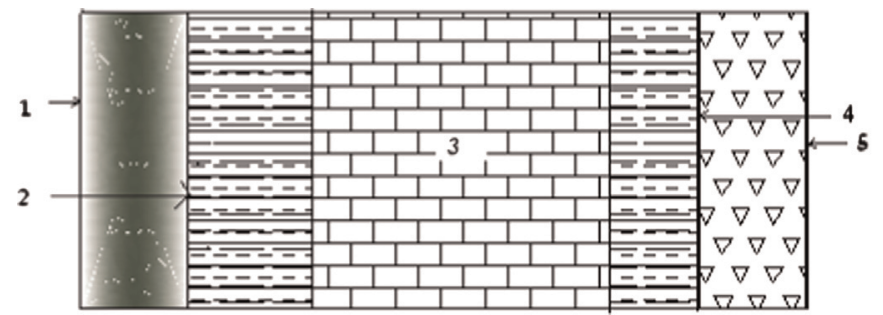

Fig. 1. Layers of a standard wall: (1) external coating (plaster, $0.6 \mathrm{~cm}$ ); (2) concrete $(1.1 \mathrm{~cm})$; (3) brick $(10 \mathrm{~cm})$; (4) concrete $(0.5 \mathrm{~cm})$ and (5) internal coating (marble, $1 \mathrm{~cm})$.

Table 2

Characteristics of the measurement systems.

\begin{tabular}{|c|c|c|c|c|}
\hline & Function & Range & Resolution & Accuracy \\
\hline \multirow[t]{5}{*}{$\mathrm{CO}_{2}$ monitor (model CO200) } & $\mathrm{CO}_{2}$ & 0-9999 ppm & $1 \mathrm{ppm}$ & $\pm(5 \% \mathrm{rdg}+50 \mathrm{ppm})$ \\
\hline & Temperature & $-10^{\circ} \mathrm{C}$ to $60^{\circ} \mathrm{C}$ & $0.1^{\circ} \mathrm{C}$ & $\pm 0.6^{\circ} \mathrm{C}$ \\
\hline & & $14-140{ }^{\circ} \mathrm{F}$ & $0.1^{\circ} \mathrm{C}$ & $\pm 0.9^{\circ} \mathrm{F}$ \\
\hline & Humidity & $0.1-99.9 \%$ & $0.1 \%$ & $\pm 3 \%(10-90 \%)$ \\
\hline & & & & $\pm 5 \%(<10 \%$ or $>90 \%)$ \\
\hline \multirow[t]{3}{*}{ Digital thermometer } & Temperature & $-20^{\circ} \mathrm{C}$ to $0{ }^{\circ} \mathrm{C}$ & $1{ }^{\circ} \mathrm{C}$ & $\pm 5.0 \%$ of $\operatorname{rdg} \pm 4$ digits \\
\hline & & $0-400^{\circ} \mathrm{C}$ & $1^{\circ} \mathrm{C}$ & $\pm 1.0 \%$ of $\operatorname{rdg} \pm 3$ digits \\
\hline & & $400-1000^{\circ} \mathrm{C}$ & $1^{\circ} \mathrm{C}$ & $\pm 2.0 \%$ of rdg \\
\hline \multirow[t]{4}{*}{ C.A 1226 thermo-anemometer } & Air velocity & $0.15-3 \mathrm{~m} / \mathrm{s}$ & $0.01 \mathrm{~m} / \mathrm{s}$ & $\pm 3 \% \mathrm{R}+0.1 \mathrm{~m} / \mathrm{s}$ \\
\hline & & $3.1-30 \mathrm{~m} / \mathrm{s}$ & $0.1 \mathrm{~m} / \mathrm{s}$ & $\pm 1 \% \mathrm{R}+0.2 \mathrm{~m} / \mathrm{s}$ \\
\hline & Temperature & $-20^{\circ} \mathrm{C}$ to $+80^{\circ} \mathrm{C}$ & $0.1{ }^{\circ} \mathrm{C}$ & $\pm 0.3 \% \mathrm{R}+0.25^{\circ} \mathrm{C}$ \\
\hline & Air flow & $0-99,999 \mathrm{~m}^{3} / \mathrm{h}$ & $1 \mathrm{~m}^{3} / \mathrm{h}$ & $\pm 3 \% \mathrm{R} \pm 0.03 *$ surf. \\
\hline
\end{tabular}

to 22:00. The probes were positioned at $1.1 \mathrm{~m}$ height from the ground level, in strict accordance with the prescriptions ASHRAE Standard 55 [17] and ISO 7730 [18]. The devices were installed from 7:00 am, and the data collection started at 8:00 am, so as to enable each probe to adapt to the environment. In most cases, thermal uniformity was difficult to achieve in buildings. Hence, in this study, the measurement of the environmental parameters was conducted at various points occupied by the occupants. In each season in 2012. All new and old buildings studied, were naturally ventilate

Despite the fact that most of the time it is indoor air temperature which is the main variable that defines an indoor ambience, in the present research work, indoor relative humidity was sampled and analysed in depth due to it being the more flexible variable. It is due to there not being a clear thermal insulation difference between new and old buildings, but what can be expected is a different hygroscopic wall behaviour. In each of the studied buildings, doors were half closed and the windows slightly open.

\subsection{PD index}

$P D$ index was associated with the relative humidity of skin $\left(P D_{\text {skin }}\right)$, the warm respiratory comfort $\left(P D_{W R C}\right)$ and the perceived quality of air at a specific time $\left(P D_{I A Q}\right)$. The man is usually inside, it is necessary that the environment is healthy and comfortable. Thermal comfort is on the health and productivity of an individual. Highly dependent on the physical, physiological and psychological. The analytical study of comfort was initiated by Fanger [19], over time, an adaptive approach is adopted. It results from field studies. These standards form the basis of standard ISO 7730 [18] and ASHRAE 55 [17]. When we want to study the discomfort caused by the moist skin in dressed people we must apply the percentage of dissatisfaction by moist skin $\left(P D_{\text {skin }}\right)$ [12] and $P D_{W R C}$ for the warm respiratory comfort [12], respectively. $P D_{W R C}$, called the percentage of dissatisfaction for warm respiratory comfort expresses the degree of discomfort caused by human respiratory tract evaporation, convection and cooling Insufficient mucous membranes. It was developed to assess the impact of the temperature and humidity of the air inhaled perception based on 14 combinations of air temperature and relative humidity. This model has a validity range of the temperature of $20-29{ }^{\circ} \mathrm{C}$ and steam partial pressure of 1000-3000 Pa (see [8]). Its expression obtained based on the air temperature $(\mathrm{Ta})$ and the partial vapour pressure $(\mathrm{Pa})$ is

$$
\begin{aligned}
& P D_{\text {WRC }} \\
& \qquad=\frac{100}{1+\exp [-3.58+0.18(30-t a)+0.14(42.5-0.01 P a)]} \%
\end{aligned}
$$

The other respiratory warm comfort index is selected acceptability $\left(A C C_{W R C}\right)$. This index is obtained by linear regression:

$A C C_{W R C}=-1.06+0.046(30-t a)+0.038(42.5-0.01 P a)$

where $(30-t a)$ is the potential convective, $(42.5-0.01 \mathrm{~Pa})$ potential and evaporative heat transfer given by the constant.

The ASHRAE recommends keeping the percentage of local dissatisfaction below $15 \%$, and the percentage of general thermal comfort dissatisfaction below $10 \%$. As we can see, this $P D$ tends to decrease when the temperature decreases and, consequently, these limiting conditions can be employed to define the optimal conditions for energy saving in the air conditioning systems.

The influence of humidity on thermal sensation may be under dynamic conditions to calculate the $P D$.

\section{Results and discussion}

\subsection{Groups of buildings}

An initial analysis of one-way ANOVA showed, taking relative humidity as the main control variable, two main groups of indoor ambiences for a significance level of 0.05 in agreement with the expected effect of wall construction materials, as can be seen in Table 3. From this table, we can conclude that indoor ambiences in new buildings showed the same behaviour, and that this is clearly different from the old buildings at a significance level of 0.05 .

On the other hand, the old buildings were not too far from the significance limit fixed for this study. Consequently, these old buildings showed certain tendencies to attaining similar ambiences, and being clearly different from the new ones. Despite 
Table 3

Buildings and two main groups of indoor ambiences with different significance level.

\begin{tabular}{lll}
\hline Building & Group of new buildings & Group of old buildings \\
\hline B7 & & \\
B10 & 64.8684 & \\
B3 & 65.4737 & \\
B5 & 66.5000 & \\
B8 & 67.9474 & \\
B1 & 68.3632 & \\
B4 & 68.9421 & \\
B13 & 68.9474 & \\
B15 & & 72.7053 \\
B6 & & 72.7368 \\
B2 & & 73.4421 \\
B14 & & 73.7368 \\
B12 & & 73.9263 \\
B9 & & $\mathbf{0 . 9 7 5}$ \\
B11 & & \\
Significance level & $\mathbf{0 . 0 5 0}$ & \\
\hline
\end{tabular}

this, old buildings are not a statistical group.

\subsection{Real sampled data}

To analyse the effect that wall construction materials have over indoor ambiences, comparison of indoor and outdoor average partial vapour pressure differences for different wall construction materials was done, as can be seen in Figs. 2-5. The partial vapour pressure difference was considered as the comparative parameter because it was the better variable in previous research works in other climatic regions that consider dry bulb temperature and relative humidity.

\subsection{Hourly statistical analysis}

From an average study, we can conclude that indoor air relative humidity is $5 \%$ higher in old buildings than in new ones during the dry season. At the same time, the average indoor air temperature in the new buildings is $1{ }^{\circ} \mathrm{C}$ higher than in the old ones. From this relationship, and in accordance with Simonson's studies [13-16], we can say that this is an isenthalpic process of the same indoor ambience. If we analyse the thermal comfort and consequences of these variations, we can say that, as a consequence of this higher relative humidity, a higher acceptability of indoor ambiences in the old buildings was obtained during the dry season, and the worst acceptability was obtained during the rainy season.
As a consequence of this different indoor partial vapour pressure, different thermal comfort conditions were obtained, as shown in Figs. 6-9, by means of the percentage of dissatisfied persons index. This index is defined by Eq. (1).

Once the average behaviour is defined, it is time to find out whether these effects and statistical results are related to the external coatings (marble or plaster, for example) or with wall construction materials (earth or parpen), and its hourly evolutions. To do this, an hourly ANOVA study for each pair of conditions was conducted. Consequently, the comparisons were between

- Indoor air behaviour in new (B7) and old (B14) buildings with plaster.

- Indoor air behaviour in new (B15) and old (B11) buildings with marble.

- Indoor air behaviour in new buildings with plaster (B7) and marble (B15) external coatings.

- Indoor air behaviour in old buildings with plaster (B14) and marble (B11) external coating.

From Figs. 10, 11 and 12, we can see that during the early working hours of the day, the effects of building wall construction materials over indoor air relative humidity are very clear. Thus, we can see that the more impermeable external coating implies a higher indoor air relative humidity during the dry season and, consequently, a better perception of indoor air.

This is the case of the old buildings using marble as external coating (B11). During the rainy season, this same building experiences a higher relative humidity, and reaches the worst indoor air acceptability of all the buildings (-0.2).

At the same time, in new buildings (B15), this kind of external coating implies, during the dry season, an increment of indoor air relative humidity and indoor air acceptability when they are compared with other external coatings, like paint and, in particular, plaster (B7 and B10). Consequently, the worst percentage of dissatisfied persons is during the rainy season (70\%), similarly as it happens with the building B11 (60\%) under these same conditions, as a clear example of the benefits of marble used as external coating in this climatic region. Finally, there does not seem to be too much of a difference in indoor ambience behaviour between plaster and paint coatings.

If we now compare the behaviour of new and old buildings (B7 and B14) and, at the same time the effect of plaster and marble external coating (B11 and B14), we obtain Figures 11 and 12. From these figures, we can conclude that it is not the effect of the external coating which shows the higher influence over a building's

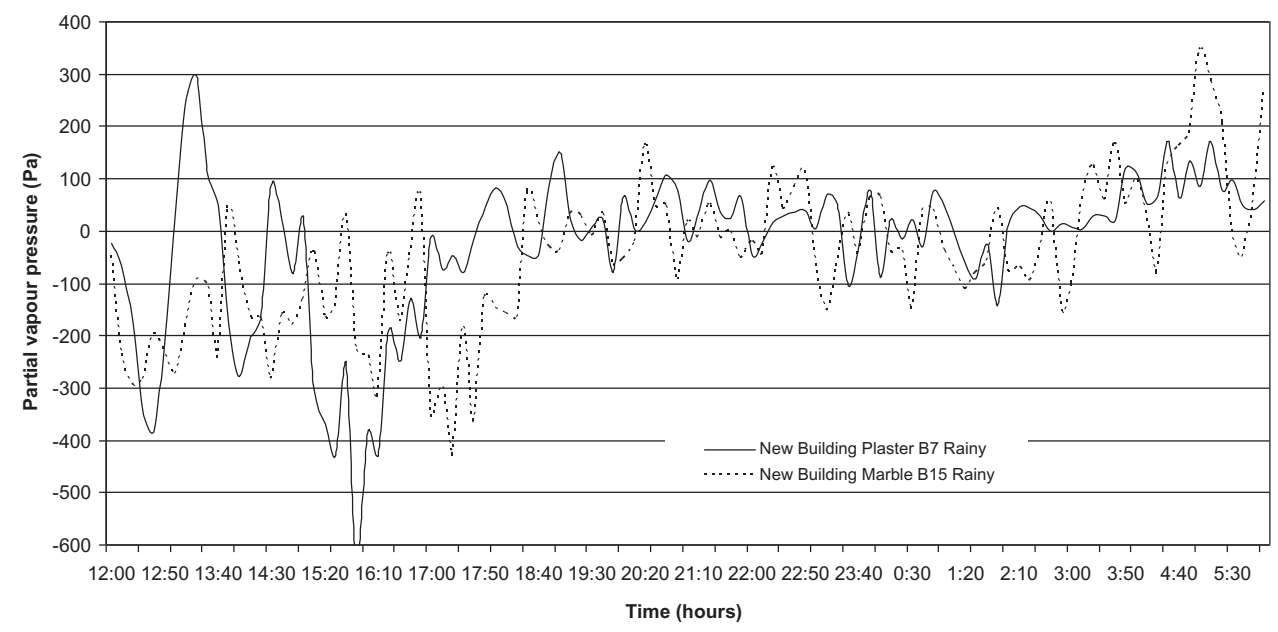

Fig. 2. Partial vapour pressure difference in new buildings with plaster and marble coatings during the rainy season. 


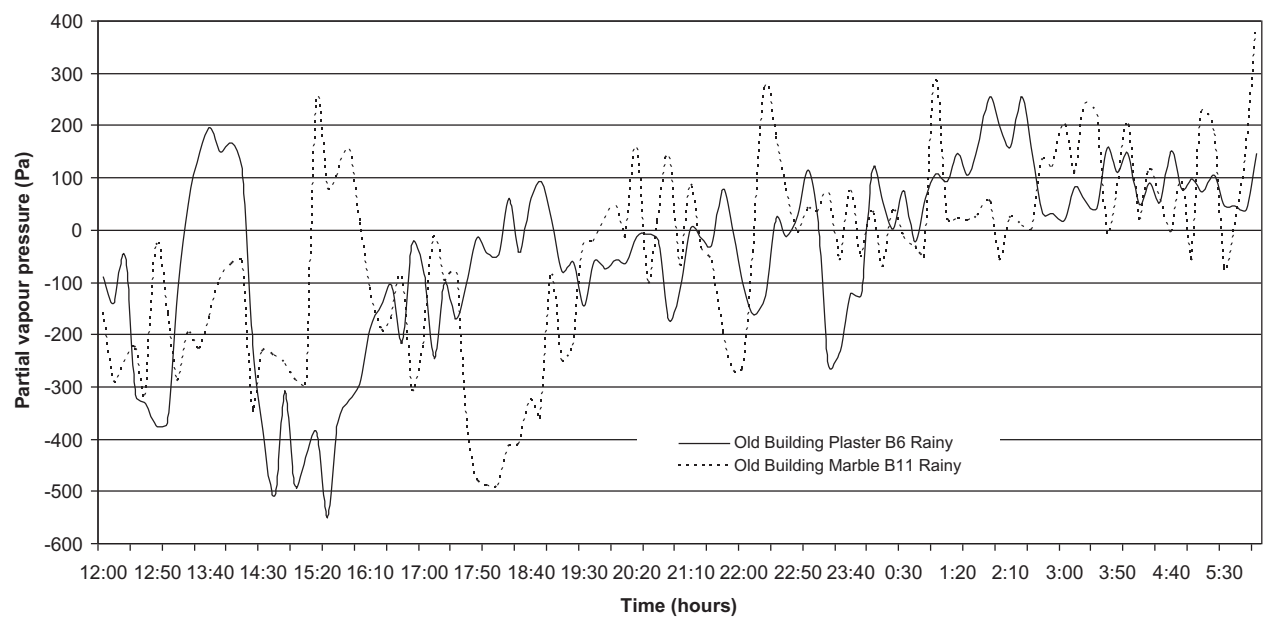

Fig. 3. Partial vapour pressure difference in old buildings with plaster and marble coatings during the rainy season.

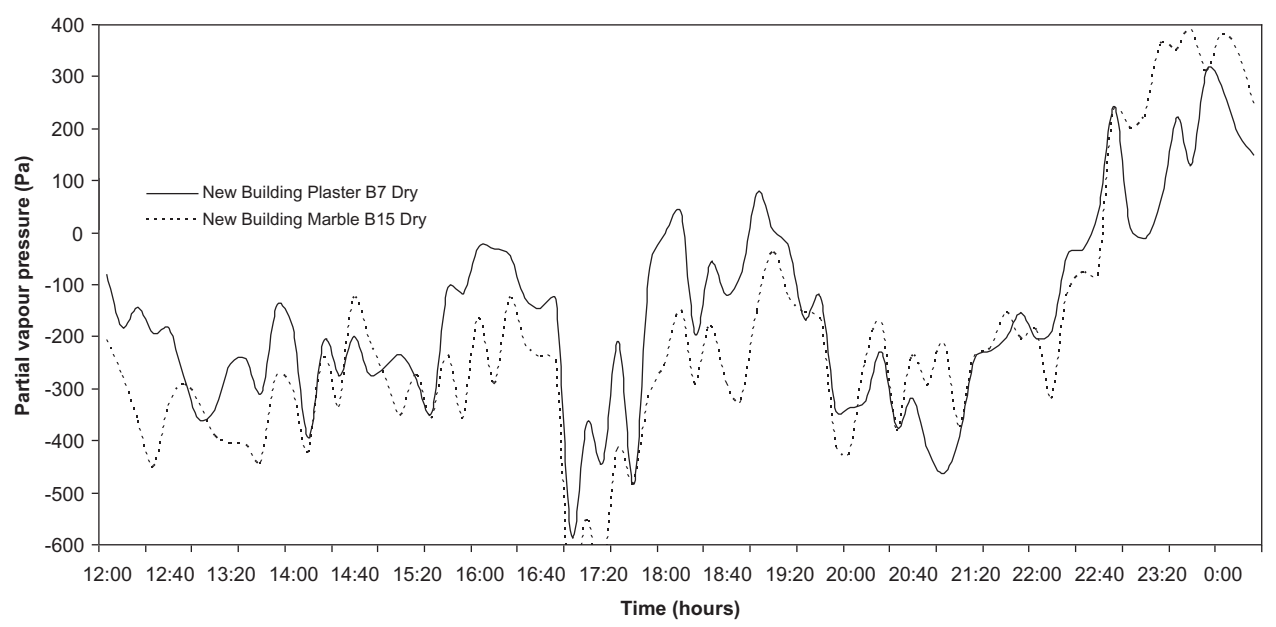

Fig. 4. Partial vapour pressure difference in new buildings with plaster and marble coatings during the dry season.

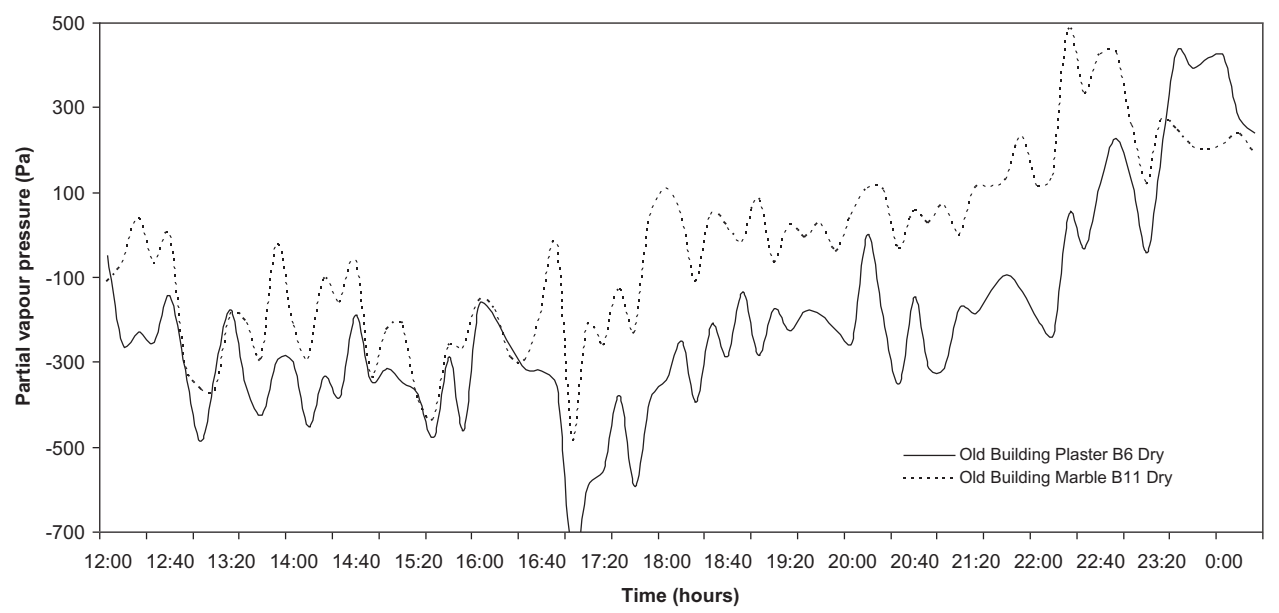

Fig. 5. Partial vapour pressure difference in old buildings with plaster and marble coatings during the dry season.

indoor ambience, but that it is the type of brick that is mainly responsible for this.

From Fig. 10, we can see the similitude between new and old buildings with plaster coating during the dry and rainy seasons. From this figure we can observe that during the working hours (07:00-17:00), there is a clear difference between new and old buildings' behaviour. Despite this, it is only statistically representative during the few initial working hours of the dry season, as can be seen in Fig. 6, with values below 0.05. Furthermore, at the exact time when the office closes (17:00), and during the four closing hour periods, there is a clear difference in indoor ambience behaviour with a significance value below 0.05 in rainy 


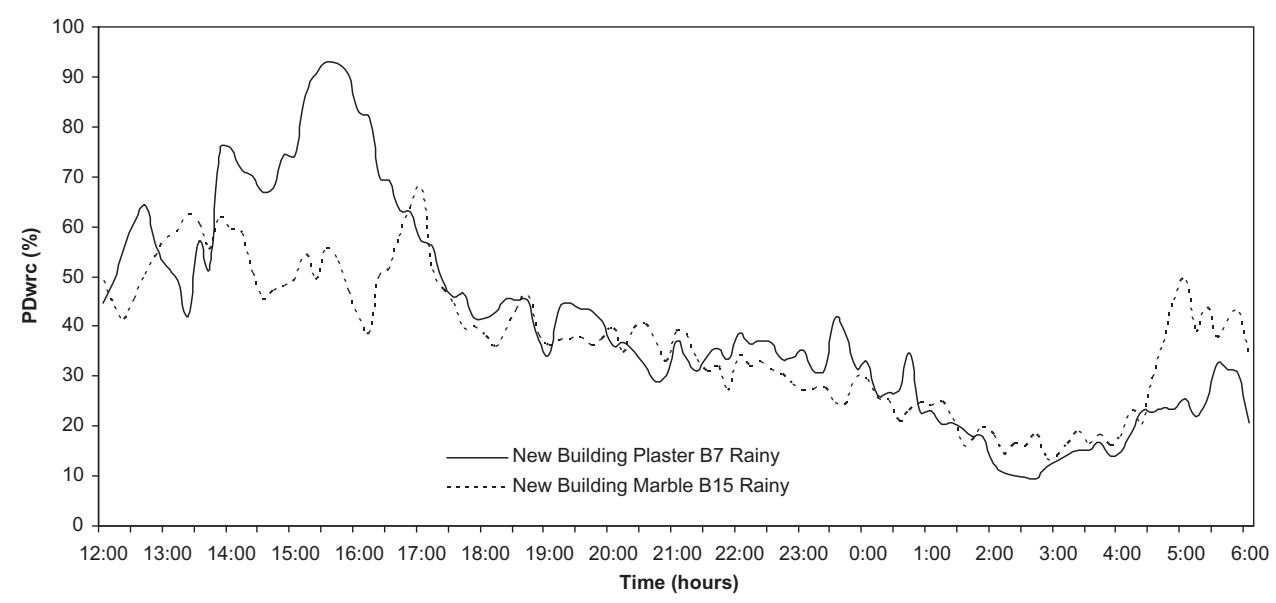

Fig. 6. Percentage of dissatisfied persons in new buildings with plaster and marble coatings during the rainy season.

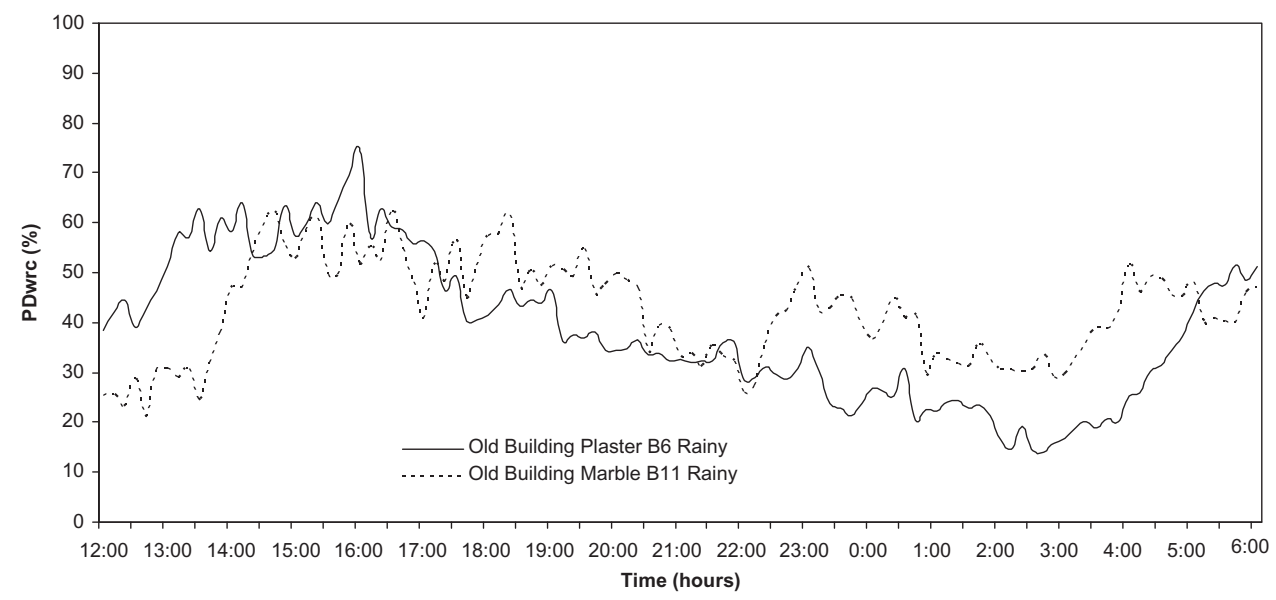

Fig. 7. Percentage of dissatisfied persons in old buildings with plaster and marble coatings during the rainy season.

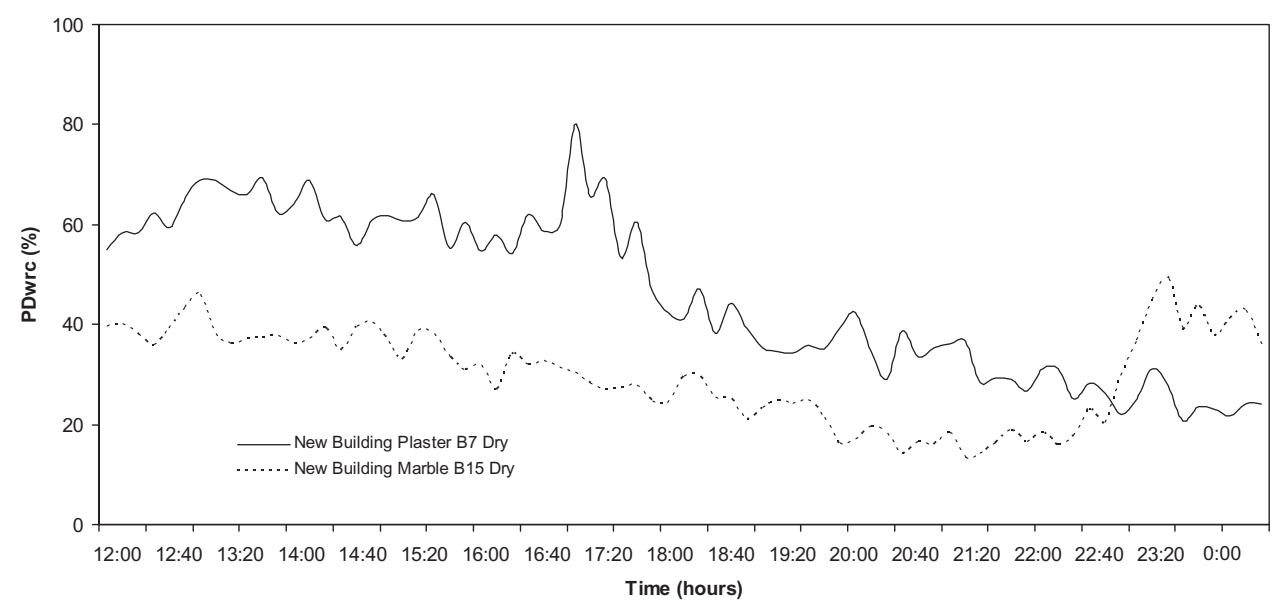

Fig. 8. Percentage of dissatisfied persons in new buildings with plaster and marble coatings during the dry season.

and, in particular, dry season. At 22:00, the hygroscopic effect of the building wall construction materials perform their activity, and the indoor ambience tends to stay at the same level up to 6:00.

During this unoccupied period, despite the fact that the significance level is clearly over 0.05 and, consequently, indoor ambiences can be considered to reach the same behaviour, we can see that there is a clear, greater tendency to reach a similar behaviour between new and old buildings during the rainy season than in the dry season.
From this difference in internal behaviour of indoor ambiences, and from the initial ANOVA study, we can conclude that there is a certain advantage in employing old building materials since they result in an improvement in indoor air relative humidity, releasing it when the level is low indoors, and adsorbing it when it is much higher. Consequently, it can improve indoor air thermal comfort and the related energy consumption.

To analyse the real effect of the building's external coatings (plaster or marble) between new and old buildings, the same 


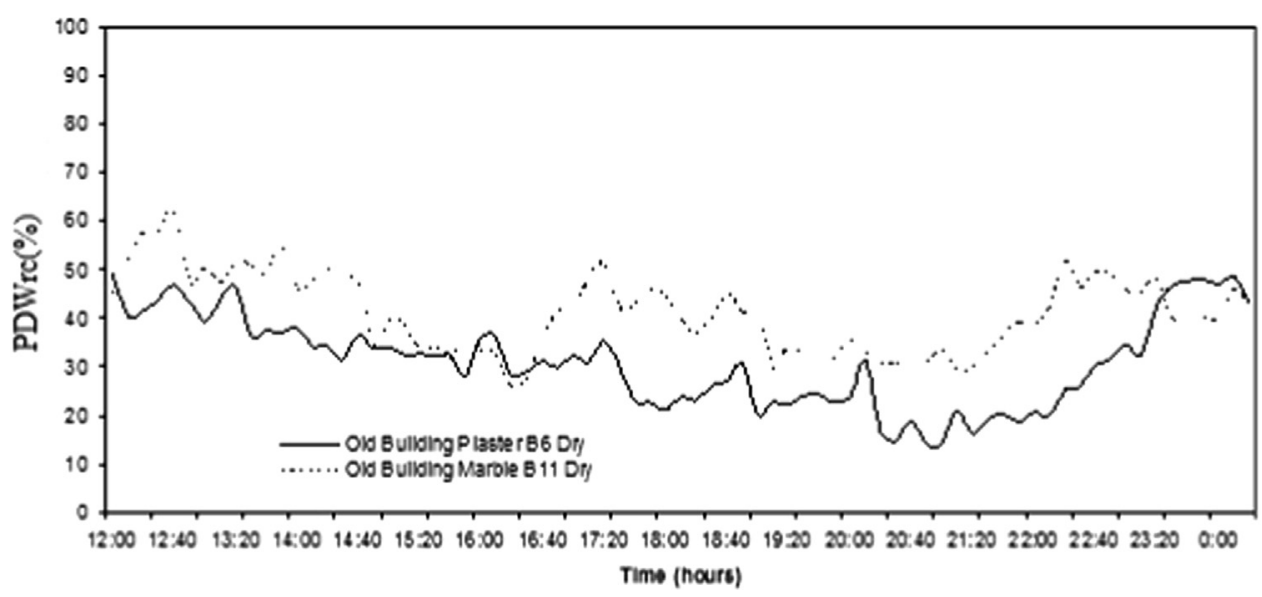

Fig. 9. Percentage of dissatisfied persons in old buildings with plaster and marble coatings during the dry season.

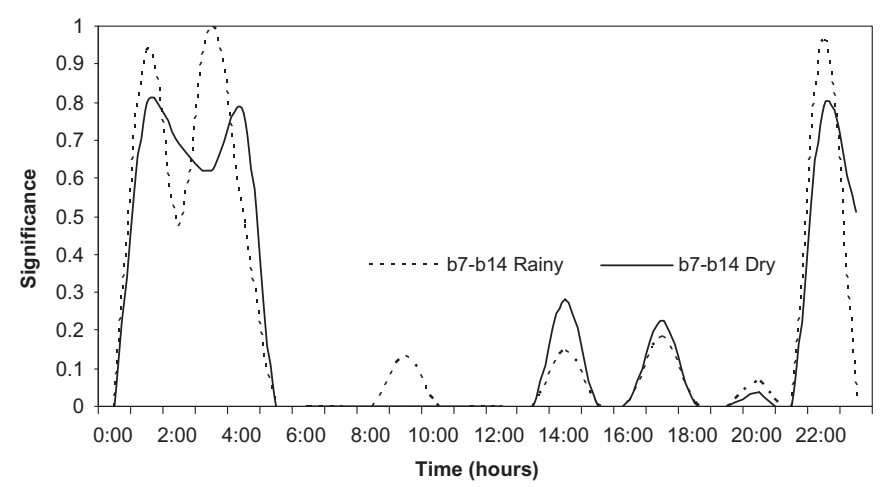

Fig. 10. Comparison of indoor air behaviour in new (B7) and old (B14) buildings with plaster.

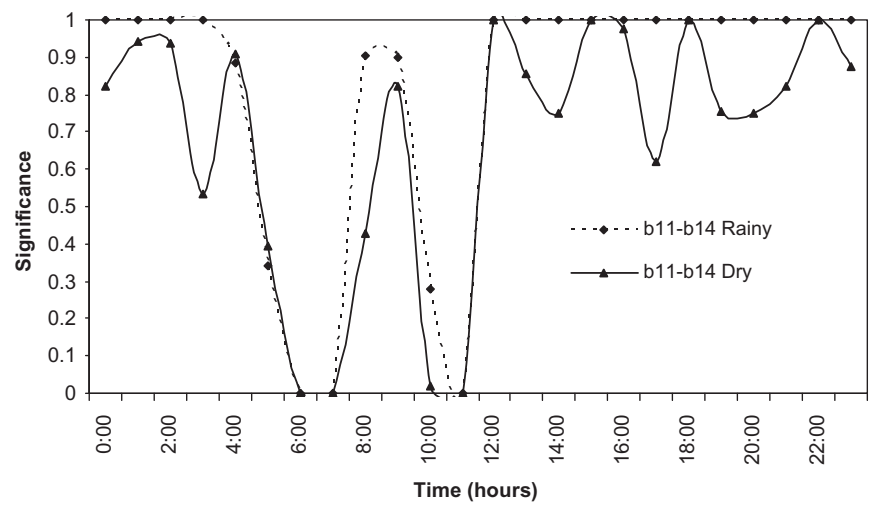

Fig. 11. Comparison of plaster (B14) and marble (B11) external coating in an old building.

hourly study was carried out, as can be seen in Figs. 11 and 12.

Fig. 11 represents the hourly ANOVA study of two old buildings with different external coating of plaster or marble. From this figure, we can conclude that only during the periods of opening time from 6:00 to 7:00, and from 10:00 to 11:00, there is a clear difference in indoor ambience behaviour. During the remaining time, there is no significant statistical difference between the ambiences. Despite this, it can be observed that in old buildings, there is a certain higher similitude in indoor ambiences during the rainy season than in the dry one. It can be related with the fact that in these very humid environments, the relative humidity exceeds that of the humid season, and the capacity of the external coating materials. Consequently, in both seasons, plaster and marble external coatings can be considered to exert a clear effect over indoor ambiences in old buildings.

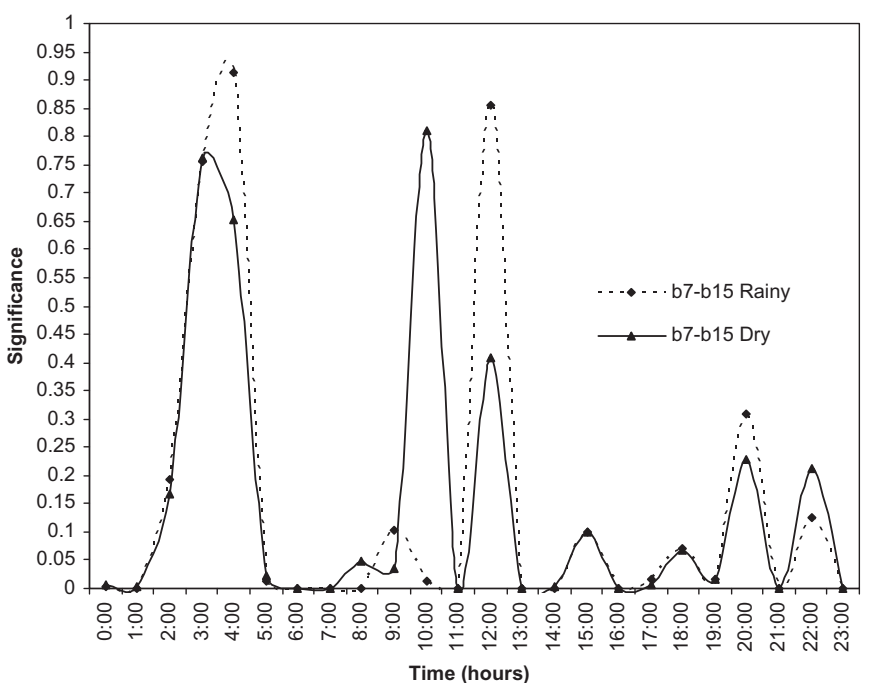

Fig. 12. Comparison of plaster (B7) and marble (B15) external coating in new building.

If we now analyse the same effect of external coatings in the new buildings, we have Fig. 12. This figure shows how, during the unoccupied period, new buildings with marble or plaster showed nearly the same indoor ambience behaviour during the dry and rainy seasons. Despite this, there is a certain tendency to reach a higher similitude during the rainy season, as can be seen in Fig. 12, with a dashed line reaching the higher values.

On the other hand, it is interesting to note that from 6:00 to 9:00, there is a clear difference in a building's indoor ambience which, after two working hours tends to converge towards nearly the same indoor ambience. After 13:00, the indoor ambiences in dry and rainy seasons showed reduced significance values of nearly 0.05 , showing two different indoor ambiences in each season and building. At 20:00, the significance level tends to increase, with the two indoor ambiences converging again.

\section{Conclusions}

In this work, an experimental study was conducted with the aim to finding out the influence of earthen brick buildings adapted to the local climate, and blocks on indoor air quality during the first hours of work in 15 office buildings. It was concluded that the 
type of season is not the more important parameter, despite the tendency towards similar ambiences during the rainy season. On the other hand, a clear difference between new and old buildings with plaster coatings during the occupation period was shown. In particular, a better indoor ambience during occupation in the old buildings was seen. At the same time, when the marble and plaster coating in old buildings was analysed, a clear difference in indoor ambience behaviour was obtained during the office opening hour. In particular, a better indoor ambience was obtained during the dry period in the old buildings when marble coatings were employed. When indoor relative humidity was analyzed, it was clearly defined as the group of new buildings under a significance value of 0.05 with an average value of $67 \%$, and a standard deviation of 1.67. At the same time, the old buildings showed an average relative humidity of $73 \%$, and a standard deviation of 0.69 for a significance level of 0.97 . The same effect, was obtained in new buildings with a marble coating during all the season.

\section{References}

[1] J.A. Orosa, A.C. Oliveira, N.M.M. Ramos, Experimental quantification of the operative time of a passive HVAC system using porous covering materials, J. Porous Media 13 (7) (2010) 637-643.

[2] J.A. Orosa, A.C. Oliveira, Sick Building Syndrome in Libraries and other Public Buildings. Chapter: Passive Methods as a Solution for the Sick Building Syndrome in Public Buildings, Springer, 2011.

[3] J.A. Orosa, A.C. Oliveira, Passive Methods as a Solution for Improving Indoor environments, Springer (2011) http://dx.doi.org/10.1007/978-3-642-17919-8.

[4] J.A. Orosa, A.C. Oliveira, A field study on building inertia and its effects on indoor thermal environment, Renew. Energy 37 (1) (2012) 89-96.
[5] J.A. Orosa, Research on local thermal comfort models, Eur. J. Sci. Res. 34 (4) (2009) 568-574.

[6] J.A. Orosa, Research on the origins of thermal comfort, Eur. J. Sci. Res. 34 (4) (2009) 561-567.

[7] J.A. Orosa, Research on general thermal comfort models, Eur. J. Sci. Res. 27 (2) (2009) 217-227.

[8] J.A. Orosa, A.C. Oliveira, A new thermal comfort approach comparing adaptive and PMV models, Renew. Energy 36 (3) (2010) 951-956.

[9] J.A. Orosa, A.C. Oliveira, Hourly indoor thermal comfort and air quality acceptance with passive climate control methods, Renew. Energy 34 (12) (2009) 2735-2742.

[10] J.A. Orosa, E.J. García-Bustelo, Permeable coverings as a sustainable solution for indoor air thermal comfort and energy saving, Energy Educ. Sci. Technol. Part A: Energy Sci. Res. 29 (1) (2012).

[11] J. Toftum, A.S. Jorgensen, P.O. Fanger, Upper limits for indoor air humidity to avoid uncomfortably humid skin, Energy Build. 28 (1998) 1-13.

[12] J. Toftum, A.S. Jorgensen, P.O. Fanger, Upper limits of air humidity for preventing warm respiratory discomfort, Energy Build. 28 (1998) 15-23.

[13] C.J. Simonson, M. Salonvaara, T. Ojanen, Improving Indoor Climate and Comfort with Wooden Structures. Technical Research Centre of Finland, Espoo, 2001.

[14] C.J. Simonson, M. Salonvaara, T. Ojalen, The effect of structures on indoor humidity - possibility to improve comfort and perceived air quality, Indoor Air 12 (2002) 243-251.

[15] C.J. Simonson, M.H. Salonvaara, Mass transfer between indoor air and porous building materials. Part I: experimental facility and material property data, Int. J. Heat Mass Transf. 50 (2007) 4527-4539.

[16] C.J. Simonson, T. Ojanen, Moisture performance of building envelops with no plastic vapour retarder in cold climates, Proc. Healthy Build. 3 (2000).

[17] ASHRAE, ANSI/ASHRAE Standard 55-2004, Thermal Environment Conditions for Human Occupancy, 2004.

[18] UNI EN ISO 7730, Moderate Thermal Environments - Determination of the PMV and PPD Indices and Specification of the Conditions for Thermal Comfort, 2006.

[19] P.O. Fanger, Comfort Thermique, McGraw Hill, New York, 1970. 